\title{
Graphite and Nickel Containing Tin Bronze-Steel Bimetals as Lead Free Bearing Materials
}

\author{
Ying Wang ${ }^{a}$, Qi Yang **, Jintian Chen ${ }^{b}$, Jianping Zhou ${ }^{b}$ \\ ${ }^{a}$ School of Materials Engineering, Shanghai University of Engineering Science, Shanghai 201620, China \\ ${ }^{b}$ Shanghai Hewei Corporation Limited, Shanghai 201615, China
}

Received: November 24, 2015; Revised: March 14, 2016; Accepted: May 7, 2016

\begin{abstract}
Ni was added into graphite-lead free tin bronze composite layers on surface of steel sheets by primary sintering mixed powders of graphite and $\mathrm{CuSn} 10$ with addition of a nickel nitrate and poly(vinyl alcohol) (PVA) solution in an ammonia decomposition atmosphere. The reduced Ni particles attached on the surface of graphite and $\mathrm{CuSn} 10$ particles help to link them together. The conjunction of graphite and $\mathrm{CuSn} 10$ matrix in the composites treated by cold rolling and second sintering is well, and no cracks can be observed at the interface between graphite and CuSn 10 matrix. The addition of Ni will improve the interface; increase hardness, anti-friction and anti-wear performance of the composites greatly. The Ni containing graphite-CuSn10 composites demonstrate better tribological performance than $\mathrm{CuSn} 10 \mathrm{~Pb} 10$ alloy, which makes them promising lead free bearing materials for heavy load engines.
\end{abstract}

Keywords: Tin bronze, Lead free, Graphite, Nickel, Composite

\section{Introduction}

Lead tin bronze-steel bimetals were usually employed as bearing materials of heavy load engines. Because of their high strength and thermal conductivity, the lead tin bronze layers were used as friction pairs. Steel sheets will further increase the strength and carry capacity of bearing materials, and reduce the amount of expensive nonferrous metals. However, lead is a harmful heavy metal and limitation has been imposed on its usage. Presently, considerable researches have been focused on developing lead free bearing materials ${ }^{1}$.

$\mathrm{CuSn} 10 \mathrm{~Pb} 10$ is one of the most common used lead tin bronzes for heavy load engine bearing materials. Because lead is a soft phase, it serves as lubricant for the bearing materials. As an excellent solid lubricant, graphite was applied into copper matrix composites as replacement of lead to improve their anti-friction property $^{2-7}$. But the interface binding between graphite and copper matrix is weak due to their incompatibility, which decreases the mechanical and tribological performance of the composites ${ }^{2-7}$. Modification techniques of graphite such as: Cu electroplating ${ }^{8,9}$, $\mathrm{Cu}$ electroless plating ${ }^{10,11}$, Ni electroplating ${ }^{12}$ and Ni electroless plating ${ }^{13-15}$ are effective routes to improve the interface. Nevertheless, these modification techniques are complicated, expensive and cannot be employed in large scale production.

In this work, the possibility of replacement of CuSn10Pb10 alloy by graphite-CuSn 10 composites was explored by comparing their tribological performance; a novel, simple, cost effective and large scale production technique was also presented to improve the interface between graphite and $\mathrm{CuSn} 10$ matrix.

\section{Experimental}

\subsection{Starting materials}

$\mathrm{CuSn10,} \mathrm{CuSn10pb10}$ and graphite powders with a particle size of $\sim 50 \mu \mathrm{m}$ and SPCC steel sheets with a thickness of

*e-mail: qiiyang@163.com
$1 \mathrm{~mm}$ were provided by Shanghai Hewei Corporation Limited. The chemical compositions of the SPCC steel sheets are C: 0.07 wt $\%$, Si: 0.10 wt $\%, \mathrm{Mn}: 0.35 \mathrm{wt} \%$, S: $0.011 \mathrm{wt} \%$ and P: $0.008 \mathrm{wt} \%$. $\mathrm{Ni}\left(\mathrm{NO}_{3}\right)_{2} \cdot 6 \mathrm{H}_{2} \mathrm{O}$ and PVA1788 purchased from Sinopharm Chemical Reagent Corporation Limited were used as received.

\subsection{Sample preparation}

Powder metallurgy techniques illustrated in Figure 1 were performed to prepare Ni containing graphite- $\mathrm{CuSn} 10$ composite layers on the surface of steel sheets. The typical large scale production processes of lead tin bronze-steel bimetals were as follow: spreading powders on the surface of steel sheets $\rightarrow$ primary sintering $\rightarrow$ cold rolling $\rightarrow$ second sintering $\rightarrow$ flattening ${ }^{16}$.

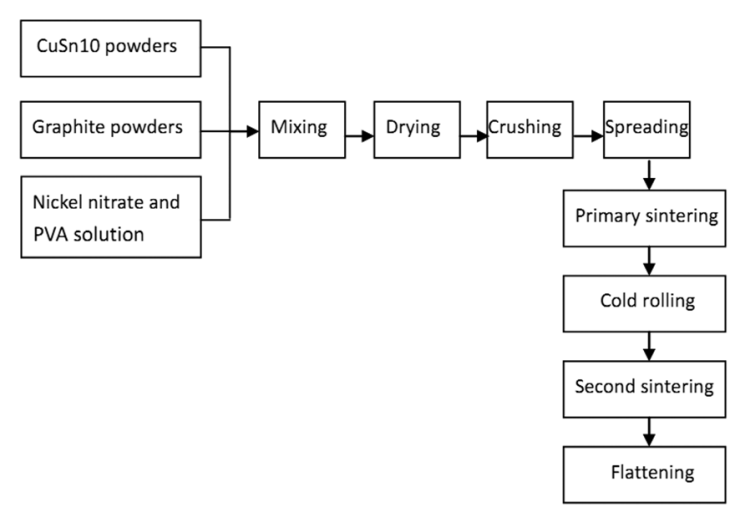

Figure 1: Flow diagram of preparation processes for graphiteCuSn10 composites containing $\mathrm{Ni}$

The solution of $\mathrm{Ni}\left(\mathrm{NO}_{3}\right)_{2}$ and PVA was prepared by dissolving $80 \mathrm{~g} \mathrm{Ni}\left(\mathrm{NO}_{3}\right)_{2} \cdot 6 \mathrm{H}_{2} \mathrm{O}$ and $5 \mathrm{~g}$ PVA in $100 \mathrm{~g}$ pure water. $\mathrm{CuSn} 10$ powders, graphite powders and the solution with weight rates of $100: 1.33,2.20,2.81,3.45: 25$ were 
mixed. Uniform slurry obtained by stirring the mixture was dried at $100^{\circ} \mathrm{C}$ for $6 \mathrm{~h}$, and the produced porous bulks were crushed into powders for following processes.

The crushed powders were loosely spread on the surface of steel sheets to form a layer with a thickness of $\sim 1 \mathrm{~mm}$. After sintered in an ammonia decomposition atmosphere at $800^{\circ} \mathrm{C}$ for $1 \mathrm{~h}$, they transform to porous layers. Cold rolling with a $10 \%$ deformation rate and second sintering at 850 ${ }^{\circ} \mathrm{C}$ for $1 \mathrm{~h}$ in an ammonia decomposition atmosphere were performed to densify the porous layers.

The weight percentage content of graphite in the obtained composite layers is $1.29 \mathrm{wt} \%, 2.11 \mathrm{wt} \%, 2.68 \mathrm{wt} \%$ and 3.27 $\mathrm{wt} \%$ (are roughly equivalent to volume percentage content of $5 \mathrm{vol} \%, 8 \mathrm{vol} \%, 10 \mathrm{vol} \%$ and $12 \mathrm{vol} \%$ ).

\subsection{Characterization and tests}

The microstructures and chemical compositions of the samples were analyzed by S-3400 Scanning Electron Microscope (SEM) and its Energy Dispersive Spectrometer (EDS). The Brinell hardness of the coatings was tested, using a $62.5 \mathrm{kgf}$ load, $30 \mathrm{~s}$ dwell time and a steel ball with a diameter of $2.5 \mathrm{~mm}$. Tribological performance tests were carried out by UMT-3MT-220 friction and wear testing instrument using a pin-on-disk technique. The size of samples was $50 \mathrm{~mm} \times 10 \mathrm{~mm} \times 3 \mathrm{~mm}$. The composite layers were taken as the plates. The spherical pins with a diameter of $6 \mathrm{~mm}$ were made of quenched chromium steel with a Rockwell hardness of 60-63. In these tests, samples are ground up to grade 1200 abrasive paper, and their surface roughness was $0.1 \pm 0.02 \mathrm{Ra}$. Each friction pair was cleaned in acetone before and after wear tests. All friction and wear tests were performed under a fixed load of $200 \mathrm{~N}$ at a sliding speed of $1 \mathrm{~m} / \mathrm{min}$. Wear rate of the samples was defined as their weight loss suffered per unit sliding distance. An electronic balance having a resolution of $0.0001 \mathrm{~g}$ was used to measure the weight loss.

\section{Results and discussions}

The aim of primary sintering in powder metallurgy processes of bimetals is to make metal particles to be connected with each other and attached on surface of steel sheets to form porous layers for following processes. Actually, for the mixture of graphite and $\mathrm{CuSn} 10$ powders without addition of $\mathrm{Ni}\left(\mathrm{NO}_{3}\right)_{2}$ and PVA solution, they are still separated particles and cannot form porous layers after primary sintering because of the presence of graphite powders. By adding $\mathrm{Ni}\left(\mathrm{NO}_{3}\right)_{2}$ and PVA solution into the graphite and $\mathrm{CuSn} 10$ powders, the porous layers on the surface of steel sheets can be obtained. Comparing Figure $2 a$ with Figure 2b, it can be observed that the dark graphite particle and gray CuSn 10 particles have smooth surface for the powders mixture without addition of $\mathrm{Ni}\left(\mathrm{NO}_{3}\right)_{2}$ and PVA solution; after adding the solution into the powders mixture, some smaller particles with a size of $1-5 \mu \mathrm{m}$ were loaded on the surface of the graphite particle and CuSn 10 particles and help to link them together. EDS was conducted to analyze the chemical compositions of the smaller particles. From the EDS patterns of point A and point $\mathrm{B}$ in Figure $2 \mathrm{~b}$ (Figure $2 \mathrm{c}$ and Figure $2 \mathrm{~d}$ ), the chemical compositions of point $\mathrm{A}$ are $\mathrm{C}(57.51 \mathrm{wt} \%), \mathrm{Cu}$ (17.01 wt \%), Sn (13.58 wt\%) and $\mathrm{Ni}(11.90 \mathrm{wt} \%)$, and the chemical compositions of point $\mathrm{B}$ are $\mathrm{C}(11.21 \mathrm{wt} \%), \mathrm{Cu}$ (20.16 wt\%), Sn (26.57 wt\%) and Ni (42.06 wt\%). The C element originates from graphite particle, $\mathrm{Cu}$ and $\mathrm{Sn}$ elements are assigned to $\mathrm{CuSn} 10$ particles, $\mathrm{Ni}$ element is attributed to the smaller particles on their surface. Because $\mathrm{Ni}\left(\mathrm{NO}_{3}\right)_{2}$ will transform to metal $\mathrm{Ni}$ at high temperature in reducing atmosphere, the smaller particles are metal $\mathrm{Ni}$.

Figure 3 shows the formation of Ni particles on the surface of graphite and $\mathrm{CuSn} 10$ particles. After CuSn10 powders, graphite powders and solution of $\mathrm{Ni}\left(\mathrm{NO}_{3}\right)_{2}$ and PVA were stirred for a period of time, the solution of $\mathrm{Ni}\left(\mathrm{NO}_{3}\right)_{2}$ and PVA will form a film on the surface of $\mathrm{CuSn} 10$ and graphite particles. Being sintered in an ammonia decomposition atmosphere, the $\mathrm{Ni}\left(\mathrm{NO}_{3}\right)_{2}$ in the film will be decomposed to $\mathrm{NiO}$, and then reduced to metal $\mathrm{Ni}$. The obtained metal $\mathrm{Ni}$ tends to form sphere morphologies to minimize its surface energy. By this technique of Ni addition, the Ni particles on the surface of CuSn10 and graphite particles will increase their connection, achieve relatively uniform distribution of $\mathrm{Ni}$ in the mixed powders, and avoid the enrichment of graphite powders in the upper layer of the mixed powders which was caused by great difference density between CuSn10 and graphite.

After primary sintering, the loosely spreading powders will transform to porous layers on the surface of steel sheets. Subsequently, cold rolling and second sintering will further dense the porous layers. Figure $4 \mathrm{a}$ and Figure $4 \mathrm{~b}$ show SEM images of densified graphite-CuSn 10 composite layers with 10 vol\% graphite and $\mathrm{Ni}$ addition. The gray part is $\mathrm{CuSn} 10$ matrix and the black part is graphite. The interface of graphite and $\mathrm{CuSn} 10$ matrix is well combined, no cracks can be observed there. Figure $4 \mathrm{c}$ and Figure $4 \mathrm{~d}$ exhibit SEM images of graphite-CuSn 10 layers with 10 vol\% graphite and no Ni addition. Apparent cracks appear at the interface between graphite and CuSn 10 matrix. Figure 4e shows the EDS pattern of point $\mathrm{C}$ (the interface between graphite and CuSn10 matrix) in Figure 4b. The chemical compositions of point $\mathrm{C}$ are $\mathrm{C}(54.95 \mathrm{wt} \%), \mathrm{Cu}$ (35.98 wt \%), Sn (5.43 $\mathrm{wt} \%)$ and $\mathrm{Ni}(3.64 \mathrm{wt} \%)$, indicating the interface between graphite and $\mathrm{CuSn} 10$ matrix contents metal $\mathrm{Ni}$ which are attributed to the smaller metal Ni particles on the surface of graphite and $\mathrm{CuSn} 10$ particles. Because graphite and $\mathrm{CuSn} 10$ are incompatible, the interface between graphite and CuSn 10 matrix is just mechanical binding. Metal Ni is compatible with both graphite and copper, so the addition of Ni will improve the interface binding of graphite and CuSn 10 matrix. The Pt element in the EDS pattern of Figure $4 \mathrm{e}$ originates from the Pt coatings on the surface of samples for SEM sample preparation.

Figure 5 compares friction coefficient curves of the composites with different graphite content and Ni addition, the composite with $10 \mathrm{vol} \%$ graphite and no Ni addition and the $\mathrm{CuSn} 10 \mathrm{~Pb} 10$ alloy. At the beginning of the abrasive tests, friction coefficient of the composite layers with different graphite content and $\mathrm{Ni}$ addition increases, and then decreases to stable state, because graphite lubricant film between wear pairs cannot be formed at this stage ${ }^{16}$. Figure 5 a demonstrates the friction coefficient curve of the composite with 5 vol\% 

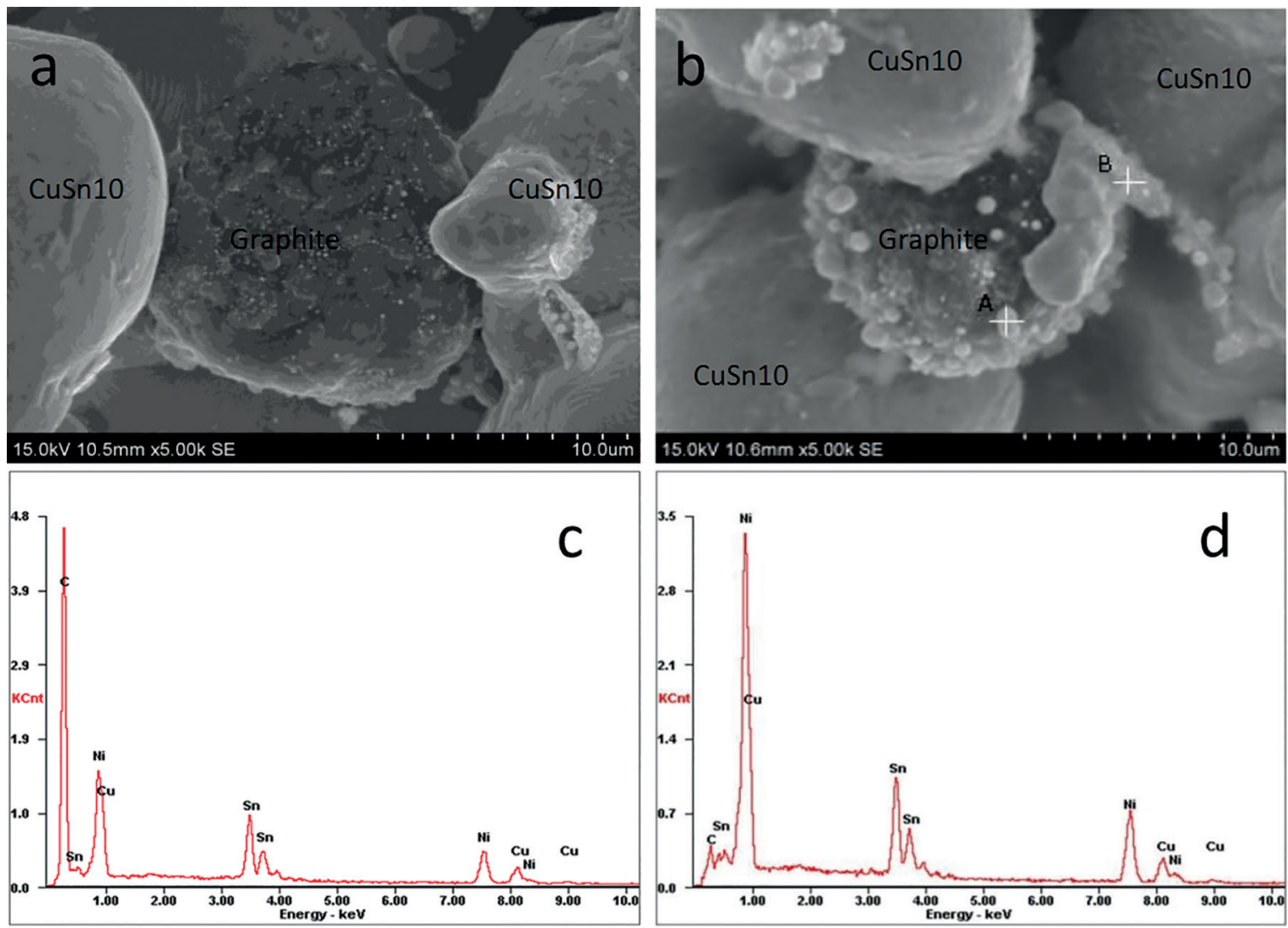

Figure 2: (a) SEM image of graphite and CuSn10 powders without adding $\mathrm{Ni}\left(\mathrm{NO}_{3}\right)_{2}$ and PVA solution treated by primary sintering, (b) Powders peered from the surface of porous graphite-CuSn10 composite layers containing Ni treated by primary sintering, (c) EDS pattern of point A in Fig. 2b, (d) EDS pattern of point B in Fig. 2b.

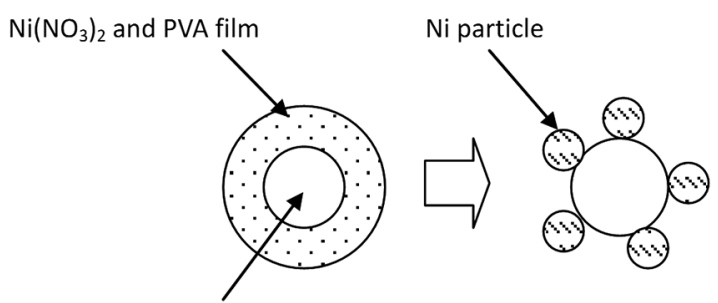

CuSn10 or graphite particle

Figure 3: Schematic diagram of formation of Ni particles attached on the surface of CuSn10 particle or graphite particle.

graphite and $\mathrm{Ni}$ addition. Its friction coefficient increases to maximum value of 0.38 after being worn for $260 \mathrm{~s}$, and then decreases to 0.23 gradually. Its friction coefficient amplitude is greater than that of composites with $8 \mathrm{vol} \%, 10 \mathrm{vol} \%, 12$ $\mathrm{vol} \%$ graphite and $\mathrm{Ni}$ addition, which indicates its unstable friction processes because its graphite content is very low and integrated lubricant film cannot be formed between wear pairs during the friction processes ${ }^{16}$. The friction processes of the composites with graphite content of $8 \mathrm{vol} \%, 10 \mathrm{vol} \%$ and $12 \mathrm{vol} \%$ are stable and their average friction coefficient is $0.19,0.12$ and 0.17 during friction processes, respectively. For the composites with graphite content above $8 \mathrm{vol} \%$, the graphite are high enough for formation of integrated lubricant films during friction processes; with increase of graphite content from 8 vol\% to $10 \mathrm{vol} \%$, the graphite lubricant film will become thicker, which further reduces the friction coefficient of the composites; with increase of graphite content from $10 \mathrm{vol} \%$ to $12 \mathrm{vol} \%$, on the contrary, the friction coefficient of the composites increases from 0.12 to 0.17 , because too high graphite content will lead to more worn metal debris in graphite lubricant film caused by decrease of wear resistance of the composites ${ }^{7,16}$. From the friction curve of no $\mathrm{Ni}$ containing composite with 10 vol\% graphite, its friction coefficient gradually increases to 0.50 and its friction processes is not stable. The cracks at the interface between graphite and $\mathrm{CuSn} 10$ matrix will induce stress concentration, which leads to more worn metal debris into graphite lubricant film. The friction coefficient of $\mathrm{CuSn} 10 \mathrm{~Pb} 10$ alloy is 0.23 . Lead in $\mathrm{CuSn} 10 \mathrm{~Pb} 10$ alloy serves as lubricant component, which leads to its stable friction processes.

From Table 1, the Ni containing composites with 5 vol $\%$, $8 \mathrm{vol} \%, 10 \mathrm{vol} \%$ and $12 \mathrm{vol} \%$ graphite exhibit hardness of 44.5, 41.3, 39.8 and 37.3 HB, respectively. Because the graphite is the soft phase in the composites, with increase of graphite content, the hardness of composites decreases. By contrast, the hardness of the no Ni containing composite with $10 \mathrm{vol} \%$ graphite is $35.0 \mathrm{HB}$, lower than that of the Ni containing composite with same graphite content. The addition of $\mathrm{Ni}$ can improve the interface between graphite and CuSn10 matrix, which leads to enhancement of hardness 

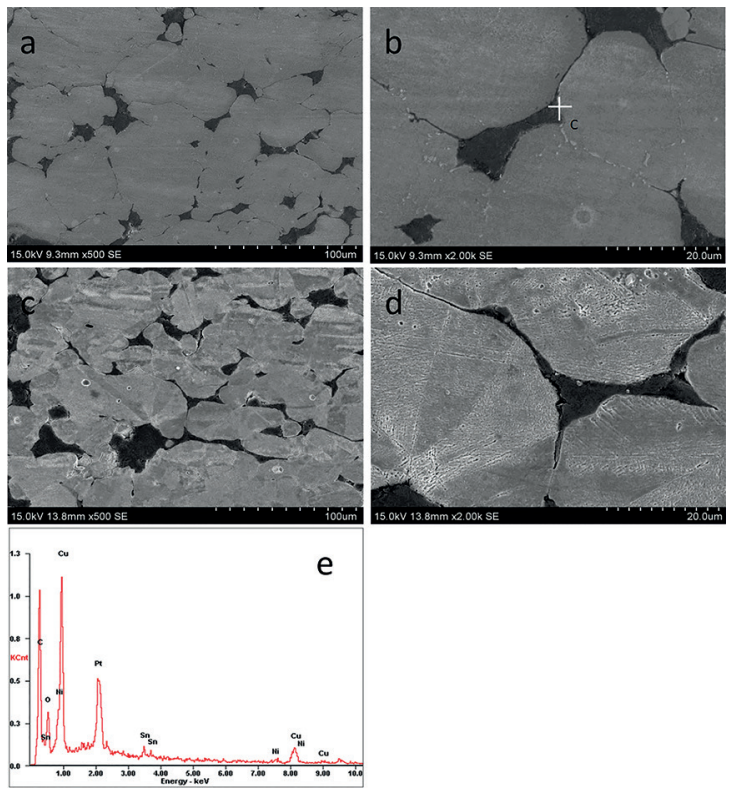

Figure 4: SEM images: (a) and (b) Ni containing graphite-CuSn10 composite layers with $10 \mathrm{vol} \%$ graphite, (c) and (d) no Ni containing graphite-CuSn 10 composite layers with 10 vol\% graphite, (e) EDS pattern of point $\mathrm{C}$ in Fig. $4 \mathrm{~b}$

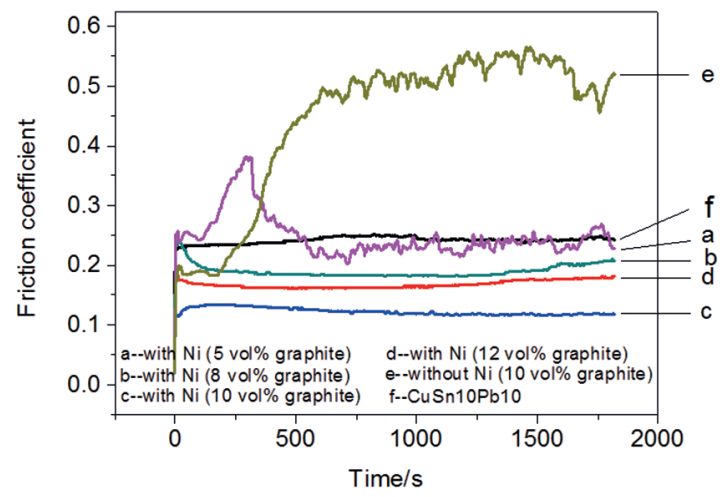

Figure 5: Friction coefficient curves of Ni containing graphite-CuSn10 composite layers with different graphite content: (a) $5 \mathrm{vol} \%$, (b) $8 \mathrm{vol} \%$, (c) $10 \mathrm{vol} \%$, (d) $12 \mathrm{vol} \%$; (e) friction coefficient curve of no Ni containing graphite-CuSn10 composite layers with $10 \mathrm{vol} \%$ graphite, (f) friction coefficient curve of $\mathrm{CuSn} 10 \mathrm{~Pb} 10$ alloy layers

of composites ${ }^{11,14}$. The hardness of CuSn10Pb10 alloy is 42.4 HB, lower than the Ni containing composite with 5 vol $\%$ graphite and higher than the Ni containing composites with $8 \mathrm{vol} \%, 10 \mathrm{vol} \%$ and $12 \mathrm{vol} \%$ graphite. Table 1 also demonstrates the wear rate of graphite-CuSn 10 composites and $\mathrm{CuSn} 10 \mathrm{~Pb} 10$ alloy. The Ni containing composites with $5 \mathrm{vol} \%, 8 \mathrm{vol} \%, 10 \mathrm{vol} \%$ and $12 \mathrm{vol} \%$ graphite exhibit wear rate of $3.6 \times 10^{-3} \mathrm{mg} / \mathrm{m}, 2.3 \times 10^{-4} \mathrm{mg} / \mathrm{m}, 1.2 \times 10^{-4} \mathrm{mg} / \mathrm{m}$ and $1.6 \times 10^{-4} \mathrm{mg} / \mathrm{m}$, respectively. Because the integrated lubricant film cannot be formed for the Ni containing composite with $5 \mathrm{vol} \%$ graphite, its wear rate is much higher than that of the composites with $8 \mathrm{vol} \%, 10 \mathrm{vol} \%$ and $12 \mathrm{vol} \%$ graphite. With increase of graphite content from 8 vol\% to $10 \mathrm{vol} \%$, the graphite lubricant film on wear surface become thicker, so the wear rate of the composites decrease slightly. On the contrary, with increase of graphite content from $10 \mathrm{vol} \%$ to $12 \mathrm{vol} \%$, the wear rate of the Ni containing composites increase slightly. For the composites with high graphite content (above $10 \mathrm{vol} \%$ graphite), their hardness become the main factor to effect their wear rate, so the decrease of hardness leads to the increase of wear rate.

Figure 6 shows the SEM images of the worn surface of $\mathrm{Ni}$ and no Ni containing graphite-CuSn10 composites with 10 vol\% graphite and $\mathrm{CuSn} 10 \mathrm{~Pb} 10$ alloy. The worn surface of $\mathrm{Ni}$ containing composite is much smoother than that of no Ni containing composite and $\mathrm{CuSn} 10 \mathrm{~Pb} 10$ alloy. There are many deep grooves and holes which can be observed on the surface of composite containing no Ni due to more metal debris worn off into graphite lubricant film. In Figure 6c, for the $\mathrm{CuSn} 10 \mathrm{~Pb} 10$ alloy, obvious adhesive wear with fractures and flakes on its surface can be observed clearly. Therefore, the Ni containing graphite-CuSn 10 composite with 10 vol\% graphite exhibits better tribological performance than that of the no Ni containing composite with same graphite contain and $\mathrm{CuSn} 10 \mathrm{~Pb} 10$ alloy.

SEM and EDS were conducted to analyze the worn surface of counterparts. The counterpart of Ni containing graphiteCuSn 10 composite with 10 vol\% graphite exhibits shallower grooves than that of the no $\mathrm{Ni}$ containing composite with 10 vol\% graphite (Figure 7a and Figure 7b). There is some wear debris attached on the surface of the counterparts. The EDS patterns in Figure $7 \mathrm{~d}$ and Figure $7 \mathrm{e}$ show that $\mathrm{Cu}$ and Sn elements are present, indicating the composite layers were peeled off and the materials were exchanged from the surface of the composite layers to the counterparts through wearing. From Figure 7c, it can be seen that the wear debris was flattened and closely attached on the surface of the counterpart. The EDS pattern in Figure $7 \mathrm{f}$ includes $\mathrm{Cu}$, Sn and high content $\mathrm{Pb}$. Because lead phase in $\mathrm{CuSn} 10 \mathrm{~Pb} 10$ alloy is very soft and have excellent ductibility, the flattened lead rich wear debris was pressed on the surface of the counterpart during wearing.

Figure 8 displays the SEM images and EDS patterns of the wear debris of graphite-CuSn10 composites and $\mathrm{CuSn10Pb10}$ alloy. The wear debris has flake-like shape. The wear debris size of Ni containing graphite-CuSn10 composite is about 5-20 $\mu \mathrm{m}$, much smaller than that of no Ni containing composite and $\mathrm{CuSn} 10 \mathrm{~Pb} 10$ alloy which have some bigger wear debris with a size of 20-60 $\mu \mathrm{m}$ (Figure 8a, Figure $8 \mathrm{~b}$ and Figure 8c). The amount of wear debris of Ni containing graphite-CuSn10 composite is much less than that of no Ni containing composite and $\mathrm{CuSn} 10 \mathrm{~Pb} 10$ alloy, most of its wear debris was dispersed in the course of milling, so that the wear debris was milled to smaller size. The EDS patterns of the wear debris in Figure 8d, Figure 8e and Figure 8f contain Fe and $\mathrm{Cr}$ elements, demonstrating the wear debris is composed by materials coming from both mating surfaces.

\section{Conclusions}

1) After primary sintering of the graphite and $\mathrm{CuSn} 10$ powders with addition of solution of $\mathrm{Ni}\left(\mathrm{NO}_{3}\right)_{2}$ and PVA, the reduced Ni particles will adhere on the surface of graphite particles and $\mathrm{CuSn} 10$ particles, and help to link them together. 
Table 1: Hardness and wear rate of graphite-CuSn10 composites and CuSn10Pb10 alloy.

\begin{tabular}{lccc}
\hline Samples & Graphite content/ vol. $\%$ & Wear rate $/ \mathrm{mg}^{-m^{-1}}$ & Hardness/HB \\
\hline Ni containing graphite-CuSn10 composite & 5 & $3.6 \times 10^{-3}$ & 44.5 \\
Ni containing graphite-CuSn10 composite & 8 & $2.3 \times 10^{-4}$ & 41.3 \\
Ni containing graphite-CuSn10 composite & 10 & $1.2 \times 10^{-4}$ & 39.8 \\
Ni containing graphite-CuSn10 composite & 12 & $1.6 \times 10^{-4}$ & 37.3 \\
no Ni containing graphite-CuSn10 composite & 10 & $8.2 \times 10^{-3}$ & 35.0 \\
CuSn10Pb10 alloy & 0 & $3.0 \times 10^{-4}$ & 42.4 \\
\hline
\end{tabular}

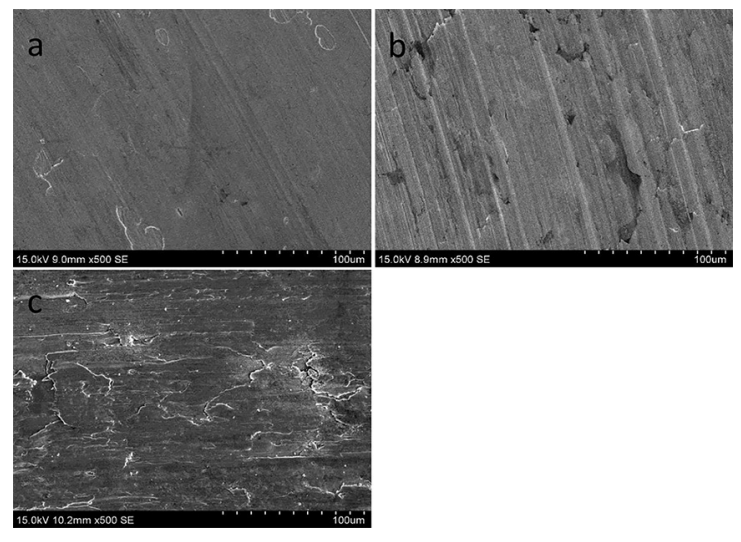

Figure 6: SEM images of the worn surface of: (a) Ni containing graphite-CuSn 10 composite layers with 10 vol\% graphite, (b) no $\mathrm{Ni}$ containing graphite-CuSn10 composite layers with $10 \mathrm{vol} \%$ graphite, (c) CuSn10Pb10 alloy layers.

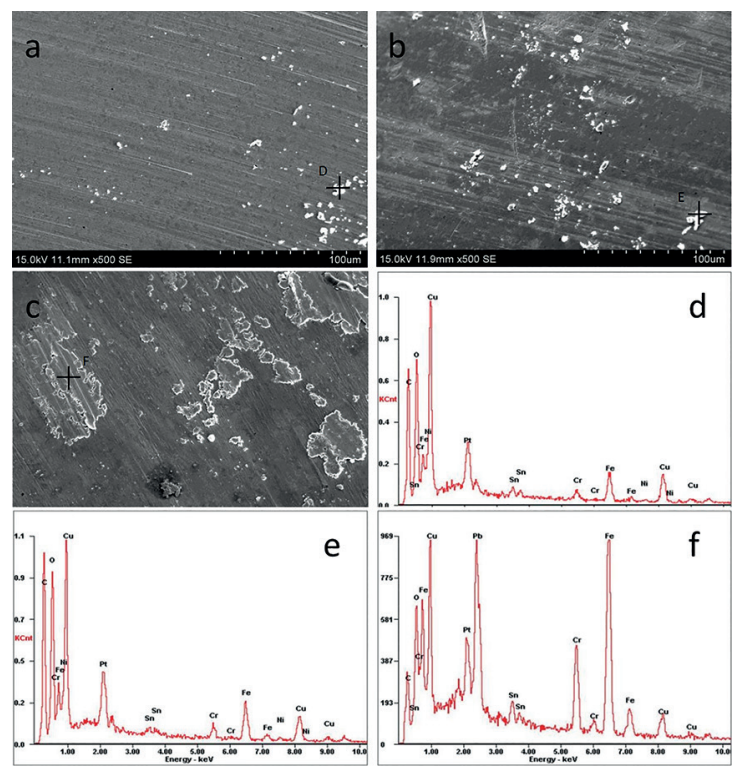

Figure 7: SEM images of the worn surface of counterparts of: (a) $\mathrm{Ni}$ containing graphite-CuSn10 composite layers with $10 \mathrm{vol} \%$ graphite, (b) no Ni containing graphite-CuSn10 composite layers with 10 vol\% graphite, (c) CuSn10Pb10 alloy layers, (d) EDS pattern of point D in Fig. 7a, (e) EDS pattern of point E in Fig. 7b, (f) EDS pattern of point $\mathrm{F}$ in Fig. 7c

2) After cold rolling and second sintering, the porous graphite- $\mathrm{CuSn} 10$ composite layers obtained by primary sintering become very dense. Metal Ni is compatible with

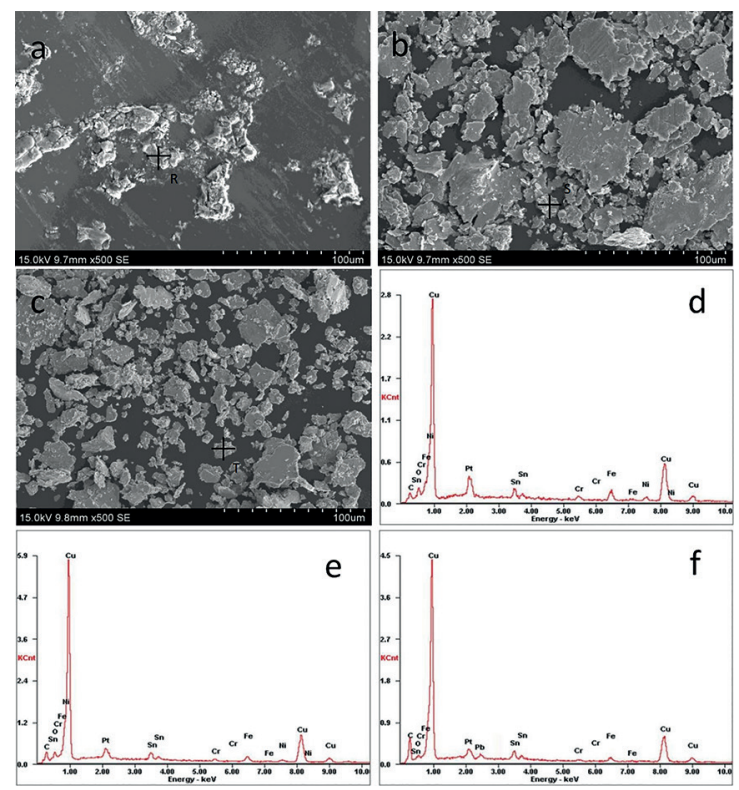

Figure 8: SEM images of the wear debris of: (a) Ni containing graphite-CuSn 10 composite layers with 10 vol\% graphite, (b) no Ni containing graphite-CuSn 10 composite layers with $10 \mathrm{vol} \%$ graphite, (c) CuSn10Pb10 alloy layers. (d) EDS pattern of point $\mathrm{R}$ in Fig. 8a, (e) EDS pattern of point $\mathrm{S}$ in Fig. 8b, (f) EDS pattern of point $\mathrm{T}$ in Fig. 8c.

both graphite and $\mathrm{CuSn} 10$ matrix. By the addition of $\mathrm{Ni}$, the interface between graphite and $\mathrm{CuSn} 10$ matrix become cracks free.

3) The addition of Ni increases the hardness, anti-friction and anti-wear properties of the composites greatly. The optimal graphite content for composite containing $\mathrm{Ni}$ is $10 \mathrm{vol} \%$. Its friction coefficient and wear rate are 0.12 and $1.2 \times 10^{-4} \mathrm{mg} / \mathrm{m}$, respectively.

4) The Ni containing graphite-CuSn 10 composites exhibit better anti-friction and anti-wear properties than that of $\mathrm{CuSn} 10 \mathrm{~Pb} 10$ alloy, which make them new promising lead free bearing materials for heavy load engines.

\section{Acknowledgments}

The work was supported by Shanghai Municipal Education Commission (High-energy Beam Intelligent Processing and Green Manufacturing) and Graduate Students Innovation Program of Shanghai University of Engineering Science (14KY0504). 


\section{References}

1. Gebretsadik DW, Hardell J, Prakash J. Friction and wear characteristics of different $\mathrm{Pb}$-free bearing materials in mixed and boundary lubrication regimes. Wear. 2015;340-341:63-72.

2. Samal CP, Parihar JS, Chaira D. The effect of milling and sintering techniques on mechanical properties of $\mathrm{Cu}$-graphite metal matrix composite prepared by powder metallurgy route. Journal of Alloys and Compounds. 2013;569:95-101.

3. Xiao JK, Zhang L, Zhou KC, Wang XP. Microscratch behavior of copper-graphite composites. Tribology International. 2013;57:38-45.

4. Rajkumar K, Kundu K, Aravindan S, Kulkarni MS. Accelerated wear testing for evaluating the life characteristics of coppergraphite tribological composite. Materials \& Design. 2011;32(5):3029-3035.

5. Rajkumar K, Aravindan S. Tribological performance of microwave sintered copper-TiC-graphite hybrid composites. Tribology International. 2011;44(4):347-358.

6. Rajkumar K, Aravindan S. Tribological behavior of microwave processed copper-nanographite composites. Tribology International. 2013;57:282-296.

7. Kestursatya M, Kim JK, Rohatgi PK. Wear performance of copper-graphite composite and a leaded copper alloy. Materials Science and Engineering: A. 2003;339(1-2):150-158.

8. Asnavandi M, Ghorbani M, Kahram M. Production of Cu-Sngraphite-SiC composite coatings by electrodeposition. Surface and Coatings Technology. 2013;216:207-214.
9. Chen L, Yu G, Chu Y, Zhang J, Hu B, Zhang X. Effect of three types of surfactants on fabrication of $\mathrm{Cu}$-coated graphite powders. Advanced Powder Technology. 2013;24(1):281-287.

10. Faraji S, Rahim AA, Mohamed N, Sipaut CS. A study of electroless copper-phosphorus coatings with the addition of silicon carbide $(\mathrm{SiC})$ and graphite $(\mathrm{Cg})$ particles. Surface \& Coatings Technology. 2011;206(6):1259-1268.

11. Liu Q, He XB, Ren SB, Zhang C, Ting-Ting L, Qu XH. Thermophysical properties and microstructure of graphite flake/ copper composites processed by electroless copper coating. Journal of Alloys and Compounds. 2014;587:255-259.

12. Lapinski J, Pletcher D, Walsh FC. The electrodeposition of nickel-graphite composite layers. Surface and Coatings Technology. 2011;205(21-22):5205-5209.

13. Kato H, Takama M, Iwai Y, Washida K, Sasaki Y. Wear and mechanical properties of sintered copper-tin composites containing graphite or molybdenum disulfide. Wear. 2003;255(1-6):573-578.

14. Xu X, Cui ZD, Zhu SL, Liang YQ, Yang XJ. Preparation of nickel-coated graphite by electroless plating under mechanical or ultrasonic agitation. Surface and Coatings Technology. 2014;240:425-431.

15. Palaniappa M, Veera Babu G, Balasubramanian K. Electroless nickel-phosphorus plating on graphite powder. Materials Science and Engineering: A. 2007;471(1-2):165-168.

16. Ru-Tie L, Xiang X, Fu-Sheng C, Jin-zhong L, Li-Ling H, YiQing Z. Tribological performance of graphite containing tin lead bronze-steel bimetal under reciprocal sliding test. Tribology International. 2011;44(2):101-105. 